\title{
EFEMERIDADE E CONSUMO CONTEMPORÂNEO: A CIRCULAÇÃO DO CAPITAL NO CONTEXTO DA OBSOLESCÊNCIA PROGRAMADA
}

\author{
Ephemerality and contemporary consumption: The capital circulation in the context of \\ planned obsolescence
}

\section{Efimeridad y consumo contemporáneo: La circulácion de lo capital en el contexto de la obsolescencia programada}

Silvânia Mineira Ribeiro Sotttani ${ }^{1}$

\begin{abstract}
Resumo
Este trabalho apresenta, a partir da constatação da obsolescência programada como um dos principais marcos da sociedade de consumo contemporânea, uma articulação entre algumas categorias marxianas - como o ciclo de produção e o tempo de circulação - há muito abandonadas por diversos teóricos do campo da Publicidade e do Consumo, e temas atualmente em destaque - como a efemeridade -, para argumentar sobre a necessidade de reflexões sobre o Consumo que considerem as esferas do material e do simbólico, em detrimento das análises recentes que, ao firmar-se apenas sobre o segundo, desconsideram sua relação com as condições materiais de produção.
\end{abstract}

Palavras chave: capital, circulação, consumo, efemeridade.

\begin{abstract}
This paper presents, from the ascertainment of planned obsolescence as one of the main landmarks of contemporary consumer society, a link between some marxian categories - such as production cycle and time of circulation - long abandoned by various theorists in the field of Advertising and Consumption, and currently highlighted themes - as the ephemerality -, to argue about the need of reflections about Consumption that consider the material and the symbolic spheres, to the detriment of the recent analysis that, since its is based only on the second, disregard its relation to the material conditions of production.
\end{abstract}

Keywords: capital, circulation, consumption, ephemerality.

${ }^{1}$ Doutoranda do Programa de Pós-Graduação em Comunicação e Cultura da Universidade Federal do Rio de Janeiro. Mestre em Ciências Sociais pela Universidade Federal de Juiz de Fora. Email: silsottani@ gmail.com. 
Efemeridade e consumo contemporâneo: A circulação do capital no contexto da obsolescência programada

de Silvânia Mineira Ribeiro Sotttani

\section{Resumen}

Este artículo presenta, a partir de la constatación de la obsolescencia programada como uno de los principales marcos de la sociedad de consumo contemporánea, una relación entre algunas categorías marxistas - como el ciclo de producción y tiempo de circulación - hace mucho abandonadas por varios teóricos en el campo de la Publicidad y lo Consumo, y temas actualmente destacados - como la efimeridad - para argumentar sobre la necesidad de reflexiones sobre el Consumo que consideren las esferas material y simbólica, en detrimento de los análisis recientes que, basándose sólo en el segundo, ignoran su relación con las condiciones materiales de producción.

Palabras-clave: capital, circulación, consumo, efimeridad.

\section{INTRODUÇÃO}

Os diagnósticos pós-modernistas sobre trabalho e capital, de uma forma geral, buscam solapar as principais categorias marxianas pela consideração de que não há mais uma grande narrativa que permita explicar o "social". Um exemplo dessa tendência é Jean Baudrillard, para quem a sociedade das imagens (ou simulacros) se sobrepôs definitivamente à sociedade da produção e do trabalho. Nessa linha podemos citar ainda Mike Featherstone e Gilles Lipovetsky, com obras prestigiadas em diversas escolas. Por outro lado, sem negar necessariamente o advento da pós-modernidade e dessa sociedade de imagens, temos autores que buscam analisa-la sob uma ótica histórica e material, como Zygmunt Bauman, Fredric Jameson e David Harvey.

Este trabalho segue essa segunda linha, pela consideração de que hoje, mais do que ultrapassadas, diversas categorias marxianas estariam adaptadas às novas circunstâncias impostas pelo atual modelo de sociedade de consumo. Nesse sentido, busca-se problematizar a questão do efêmero e do perecível - mercadologicamente conhecidos como obsolescência programada - a partir do ciclo do capital em Marx. Em especial, pelo argumento de que a preocupação marxiana com as mercadorias perecíveis (que não se prestariam a ser objeto ótimo de exploração capitalista) estaria hoje invertida, a saber: o capital se apropriou do discurso da efemeridade para agilizar o tempo de circulação das mercadorias.

Essa apropriação só pode se dar, entretanto, se considerarmos que, na condição pósmoderna, como Harvey denominou nosso momento histórico, o valor simbólico se sobrepõe às características tangíveis, o que possibilita a construção de discursos que alteram nossa percepção 
Efemeridade e consumo contemporâneo: A circulação do capital no contexto da obsolescência programada

de Silvânia Mineira Ribeiro Sotttani

sobre o conceito de efemeridade, agora não mais atrelado à durabilidade material dos bens. Nesse sentido, a argumentação deste trabalho busca conciliar os elementos culturais presentes nos discursos da pós-modernidade, como aceleração, velocidade e fluidez dos estilos de vida, com os elementos econômicos (produção, circulação, trabalhos aleatório e redundante) que envolvem a obsolescência programada, para lançar luzes sobre a seguinte questão: considerando a prática de converter valor simbólico em valor econômico, não teria a efemeridade sido incorporada pelo capitalismo para garantir a sua reprodução?

\section{O TEMPO DE CIRCULAÇÃO N’O CAPITAL}

Ao apresentar o ciclo do capital industrial, Marx alerta para a questão da velocidade do tempo de circulação, em capítulo especialmente dedicado ao tema. Considerando o ciclo DM...P...M'-D"2 (sendo as reticências os momentos que a circulação está "interrompida" pelo processo de produção), afirma o autor que conforme a rapidez com que o capital abandone a forma de mercadoria e assuma a forma de dinheiro (velocidade da venda), tão mais rápido ampliar-se-á a escala de reprodução do capital.

Ou seja, "todo o esforço do capital está voltado, desde sempre, para a redução do tempo de realização desse ciclo total" (DANTAS, 2006: 57), de forma que o capital adiantado (D) se converta em capital realizado (D'). Nesse sentido, “o processo de produção não passa de um elo intermediário inevitável, de mal necessário do mister de fazer dinheiro". (MARX, 2008: 67), uma vez que é essa interrupção que permite que $\mathrm{M} 1\left(\mathrm{Mp}+\mathrm{F}^{3}\right)$ se transforme numa mercadoria diversa, de maior valor e diversas formas de uso: M2, que vai se transformar novamente em dinheiro.

O tempo de produção é maior do que o tempo de trabalho. A diferença entre ambos é o excesso do tempo de produção sobre o tempo de trabalho. Esse excesso decorre de o capital produtivo encontrar-se em estado latente na esfera da produção, sem funcionar no processo de produção, ou em virtude de funcionar no processo de produção sem estar no processo de trabalho. A parte do capital produtivo latente, mantida disponível como condição do processo de produção, não gera produto nem forma valor. É capital parado, embora essa pausa constitua condição do fluxo ininterrupto do processo de produção. [...] Daí a tendência da produção capitalista de reduzir ao máximo possível o excesso do tempo de produção sobre o tempo de trabalho (MARX, 2008: 138139).

\footnotetext{
${ }^{2} \mathrm{D}=$ capital; $\mathrm{M}=$ mercadoria e $\mathrm{P}=$ produção.

${ }^{3}$ Meios de Produção + Força de Trabalho
} 
Efemeridade e consumo contemporâneo: A circulação do capital no contexto da obsolescência programada

de Silvânia Mineira Ribeiro Sotttani

Além desse tempo de transformação na etapa da produção, o capital também encontra barreiras temporais durante a circulação, como no momento da venda das mercadorias, a etapa que "toma" mais tempo do processo da conversão de mercadorias em dinheiro: "Como dinheiro, o valor encontra-se em forma sempre conversível. Como mercadoria, tem primeiro que converter-se em dinheiro, de adquirir a figura da permutabilidade imediata e por isso capaz de operar a qualquer momento". (MARX, 2008: 141).

Soma-se ao tempo gasto na sua conversão em dinheiro, a questão da perecibilidade do valor de uso da mercadoria. "A forma da existência das mercadorias, sua vida como valores-deuso, traça determinados limites à circulação do capital-mercadoria M'-D'” (MARX, 2008: 142). Dessa forma, se não forem objeto de consumo no prazo necessário, as mercadorias perdem, com seu valor-de-uso, a propriedade de serem portadoras do valor-de-troca, ou seja, termina o tempo de circulação do capital-mercadoria. A perecibilidade foi vista por Marx, portanto, como um risco: "Quanto mais perecível uma mercadoria, tanto mais estreito o limite que antepõe ao tempo de sua circulação, tanto menos se presta a ser objeto da produção capitalista". (MARX, 2008: 143). Por essas questões, afirma-se que "quanto mais são ideais as metamorfoses de circulação do capital - isto é, quanto mais se torna o tempo de circulação = zero, ou mais se aproxima de zero, tanto mais funciona o capital, tanto maiores se tornam sua produtividade e produção de mais-valia" (MARX, 2008: 140).

Notamos, portanto, que, considerando o tempo gasto na circulação, a perecibilidade era vista como mais um entrave para a realização do capital. Importante ressaltar que produtos como alimentos continuam se enquadrando dentro da problemática apresenta por Marx referente aos riscos que o tempo de circulação pode trazer para o valor-de-uso. Não se trata, portanto, de negar isso, mas de problematizar essa questão dentro da atual Sociedade do Espetáculo, em que os discursos que incentivam a efemeridade e produzem a sensação de perecibilidade mesmo de bens duráveis permitem reduzir o tempo de circulação, ao invés de se colocarem como um problema para ela, o que comumente se chama hoje de obsolescência programada. Seria, portanto, uma nova percepção sobre os produtos, construída através dos artefatos simbólicos dessa nova era, o que permite essa inversão no valor do bem perecível? De antemão, torna-se necessário entender melhor como o simbólico foi incorporado pelo capital para ser convertido em capital econômico.

\section{O DOMÍNIO DO SIMBÓLICO}


Efemeridade e consumo contemporâneo: A circulação do capital no contexto da obsolescência programada

de Silvânia Mineira Ribeiro Sotttani

Uma das mais recorrentes referências no debate sobre o império das imagens na sociedade consumista é, sem dúvidas, a obra Sociedade do Espetáculo (1997), do francês Guy Debord. Com orientação claramente marxiana, Debord busca lançar luzes sobre as causas do espetáculo ter se tornado o modelo dominante da nossa sociedade. Apoiado em Lukàcs, com quem apresenta profícuo diálogo, enfatiza a extrema fragmentação e separação dos homens e suas atividades produtivas nos dias de hoje como geradoras do império da contemplação em oposição à atividade produtiva.

Em outras palavras, apenas contemplamos as transformações, não mais participamos ativamente delas, sendo atividade um conceito diretamente relacionado a trabalho produtivo e transformador. O desenvolvimento capitalista afastou o homem da relação com a natureza: este só acompanha a transformação, não mais a executa."Essa submissão cresce ainda mais porque, quanto mais aumentam a racionalização e a mecanização do processo de trabalho, tanto mais a atividade do trabalhador perde seu caráter de atividade para tornar-se uma atitude contemplativa" (LUKÀCS apud DEBORD, 1997: 27).

Numa das mais citadas frases do livro, afirma: “O espetáculo não é um conjunto de imagens, mas uma relação social entre pessoas, mediada por imagens" (DEBORD, 1997: 14). Trata-se, portanto, de uma visão de mundo, mais do que apenas um conjunto de imagens, fruto do modo de produção existente. "Sob todas as suas formas particulares, o espetáculo constitui o modelo atual da vida dominante na sociedade [...] a linguagem do espetáculo é constituída de sinais da produção reinante, que são ao mesmo tempo a finalidade última dessa produção" (DEBORD, 1997: 14-15 - grifos do original). Apesar, isto posto, dessa aparente ênfase nas imagens circulantes, Debord afirma que o espetáculo também está no material, nas mercadorias, uma vez que esses bens são construídos por dispositivos do espetáculo, como a publicidade, o design e a moda.

\footnotetext{
Por esse movimento essencial do espetáculo, que consiste em retomar nele tudo o que existia na atividade humana em estado fluido, para possuí-lo em estado coagulado, como coisas que se tornaram o valor exclusivo em virtude da formulação pelo avesso do valor vivido, é que reconhecemos nossa velha inimiga, a qual sabe tão bem, à primeira vista, mostrar-se como algo trivial e fácil de compreender, mesmo sendo tão complexa e cheia de sutilezas metafísicas, a mercadoria (DEBORD, 1997: 27 - grifos do original).
}

A mercadoria abarca, portanto, as características do vivido, e constitui-se como a principal marca do que Debord denominou de sobrevivência ampliada, a saber: o continuado consumo não gera satisfação, mas um estado constante de privação, o que possibilita a aceitação 
Efemeridade e consumo contemporâneo: A circulação do capital no contexto da obsolescência programada

de Silvânia Mineira Ribeiro Sotttani

dos discursos do efêmero. Seria a segunda revolução industrial, em que o consumo alienado torna-se um dever do indivíduo separado das forças produtivas. Passa-se a ver o proletário não mais como operário (cujo foco era garantir a força de trabalho), mas como consumidor (que precisa atender a abundância de mercadorias), num suposto humanismo que, nada mais é, do que a negação total do homem. "O espetáculo é o momento em que a mercadoria ocupou toda a vida social” (DEBORD, 1997:30).

No entendimento desse processo, é fundamental compreender o conceito de fetichismo da mercadoria, já que talvez ele seja a melhor formulação teórica a aproximar o bem material e seu valor enquanto significado/simbolismo. "É a partir da ampliação do conceito que é possível estabelecer uma leitura e uma compreensão sobre a problemática da sociedade das imagens na contemporaneidade: da relação entre o concreto e o abstrato, entre o material e o virtual, entre a representação e o simulacro, que nos é apresentando por Marx, a partir da mercadoria como fetiche" (FONTENELE, 2002: 282). Para compreender a mercadoria tanto como bem econômico, quanto como objeto estético, a caracterização de Terry Eagleton é fundamental:

uma caricatura amedrontada do objeto artístico autônomo, ao mesmo tempo reificada num objeto brutalmente singular e virulentamente antimaterial na sua forma; densamente corpórea $e$ fugidiamente espectral... o lugar de uma curiosa perturbação das relações entre o espírito e os sentidos, a forma e o conteúdo, o universal e o particular: ela é, ao mesmo tempo não é, um objeto, uma falsa concretização mas também uma falsa abstração das relações sociais. Numa lógica mistificante - 'agora você vê, agora você não vê -, a mercadoria está ao mesmo tempo presente e ausente; ela é uma entidade tangível cujo significado é inteiramente imaterial e está sempre alhures, nas suas relações formais de troca com outros objetos. Seu valor é excêntrico a si mesmo, sua alma ou essência deslocado para outra mercadoria, cuja essência está igualmente noutro lugar, num diferir incessante de identidade (EAGLETON, 1993: 155 - grifos nossos).

Estamos tratando, pois, não da forma da mercadoria, mas da forma-mercadoria, ou seja, o quanto ela abarca em si as relações estabelecidas entre os homens e tem ligação com o que é valorizado socialmente em determinada época. Ao desenvolver uma análise da marca McDonalds, Fontenele problematiza a noção de forma-mercadoria, e afirma que seu estágio mais avançado seria a forma-publicitária: "o que se consome é um estilo de vida e nada escapa a essa imaterialização que tomou conta do social... a cultura tornou-se peça central na máquina reprodutiva do capitalismo, a sua nova mola propulsora" (FONTENELE, 2002:289).

Nota-se, nas afirmações da autora, a relação direta com o sistema produtivo vigente que possibilita o consumo cultural, mesmo que esse pareça se dar apenas em vista dos aspectos simbólicos (de fato, como é possível perceber, eles são predominantes). Trata-se, portanto, de um sistema produtivo fortemente integrado à produção cultural, mesmo que as imagens passem a 
Efemeridade e consumo contemporâneo: A circulação do capital no contexto da obsolescência programada

de Silvânia Mineira Ribeiro Sotttani

circular aparentemente descoladas do mundo material da produção. Essa aparente dissociação faz com que as imagens possam ser tomadas como o sintoma de uma cultura que se tornou descartável, mas, nem por isso, menos necessária no estágio atual da sociedade capitalista. “A descartabilidade da cultura é a própria condição para a reprodução do capitalismo 'de imagens"” (FONTENELE, 2002:289).

\section{COMPRESSÃO DO TEMPO E EFEMERIDADE NA ERA DA ACUMULAÇÃO FLEXÍVEL}

Assim, vemos nos dias de hoje que o investimento em imagem é tão importante quanto em meios de produção. Tal como aposta David Harvey em A Condição Pós-Moderna (2012), mais do que a superação das categorias marxianas, o que temos é a sua sofisticação, adaptadas à era da acumulação flexível, em que valores como a efemeridade passam a ser incorporados.

A tese central do livro de Harvey é de que as grandes mudanças nas práticas culturais, políticas e econômicas que temos vivenciado a partir dos anos 70 estão vinculadas à forma como experimentamos o tempo e o espaço, que, entretanto, não refletem uma sociedade inteiramente nova, mas ainda baseada em regras básicas de acumulação capitalista. Assim, o pós-modernismo não seria tanto um conjunto de ideias novas quanto uma nova condição histórica. Cabe, portanto, a questão: em que medida as grandes mudanças percebidas merecem o nome de pósmodernidade?

Para Harvey, o espetáculo é que garante a expansão do sistema capitalista. Apenas com a indústria fordista, essa expansão seria impensável, já que mesmo bens tangíveis, hoje, dependem do espetáculo. Assim, a tese do autor é de que o espetáculo é uma sofisticação do capitalismo para continuar se expandindo e a acumulação flexível seria o marco da transição da modernidade para a pós-modernidade. A pós-modernidade seria, então, uma expressão para a exacerbação da fragmentação, em oposição a Lyotard (fundador do termo pós-moderno) para quem essa era seria o fim das grandes narrativas. O marxismo se sofisticou/adaptou, mas continua sendo uma “explicação" para o social, no que podemos considerar uma atualização da visão marxiana.

No capítulo 17 do citado livro - "A Compressão do Tempo-Espaço e a Condição PósModerna" - o autor analisa a questão da efemeridade e da volatilidade, ao afirmar que "temos vivido nas duas últimas décadas uma intensa fase de compressão do tempo-espaço que tem tido um impacto desorientado e disruptivo sobre as práticas político-econômicas, sobre o equilíbrio 
Efemeridade e consumo contemporâneo: A circulação do capital no contexto da obsolescência programada

de Silvânia Mineira Ribeiro Sotttani

do poder de classe, bem como sobre a vida social e cultural" (HARVEY, 2012: 257). A aceleração do tempo de giro na produção [cita vários exemplos, como o just in time] envolve acelerações paralelas na troca e no consumo e, em relação a esse último, traz duas mudanças importantes: a moda em mercados de massa e a passagem do consumo de bens para o consumo de serviços.

Trata-se, pois, de uma era com ênfase nos valores e virtudes da instantaneidade e da descartabilidade e suas consequências sobre os indivíduos: "significa ser capaz de atirar fora valores, estilos de vida, relacionamentos estáveis, apego a coisas, edifícios, lugares, pessoas e modos adquiridos de ser e agir" (HARVEY, 2012:258). Afirma que Tofler faz eco às ideias de Simmel, ao afirmar que "o impulso acelerado da sociedade mais ampla golpeou a experiência cotidiana do indivíduo" (TOFLER apud HARVEY, 2012:258).

Harvey aborda a importância da manipulação do gosto e da opinião pela publicidade para dominar a produção da volatilidade. Para o autor, "significa construir novos sistemas de signos e imagens, o que constitui em si mesmo um aspecto importante da condição pós-moderna" (HARVEY, 2012:259). O autor afirma a relação com Baudrillard, que diz estar ultrapassada a análise que se prende na produção de mercadorias, já que o capitalismo agora tem preocupação predominante com a produção de signos.

Dadas as pressões de aceleração do tempo de giro (e de superação das barreiras espaciais), a mercadificação de imagens do tipo mais efêmero seria uma dádiva divina do ponto de vista da acumulação do capital, em particular quando outras vias de alívio da superacumulação parecem bloqueadas. A efemeridade e a comunicabilidade instantânea no espaço tornam-se virtudes a ser exploradas e apropriadas pelos capitalistas para seus próprios fins (HARVEY, 2012:260).

Ao estabelecer essa relação, lembramos que, para Marx, a diminuição no tempo de circulação seria ótimo e que, portanto, não se trata de considerar "ultrapassadas" as categorias marxianas, mas o investimento em imagem tão importante quanto em fábricas e maquinário nos dias de hoje. Está posta, na citação acima, a importância de que o capital se aproprie da efemeridade/perecibilidade para continuar sua expansão.

Nesse sentido, aponta o papel do simulacro no pós-modernismo: a diferença entre o original e a cópia é quase impossível de ser percebida e as identidades são dependentes, cada vez mais, dessas imagens. Ressalta-se que o autor está falando não apenas de identidades individuais, mas também corporativas, institucionais e políticas. Citando Daniel Bell, Harvey aborda as diferenças nas condições de trabalho nessa indústria de produção de imagens através do conceito 
Efemeridade e consumo contemporâneo: A circulação do capital no contexto da obsolescência programada

de Silvânia Mineira Ribeiro Sotttani

de "massa cultural" (não os criadores, mas os transmissores da cultura), envolvidos diretamente com a produção da efemeridade.

\begin{abstract}
Toda essa indústria se especializa na aceleração do tempo de giro por meio da produção e venda de imagens. Trata-se de uma indústria em que reputações são feitas e perdidas da noite para o dia, onde o grande capital fala sem rodeios e onde há um fermento de criatividade intensa, muitas vezes individualizada, derramado no vasto recipiente da cultura de massa serializada e repetitiva. É ela que organiza as manias e modas, e, assim fazendo, produz a própria efemeridade que sempre foi fundamental para a experiência da modernidade. Ela se torna um meio social de produção de sentido de horizontes temporais em colapso de que mesma, por sua vez, se alimenta tão avidamente (HARVEY, 2012:262).
\end{abstract}

Essa configuração gera, para o autor, uma perda do sentido de futuro, exceto na medida em que possa ser descontado no presente. Cabe a pergunta: como manter um sentido de continuidade? Harvey afirma uma crise da lógica explicativa tal como denominou Baudrillard e cita Lyotard: o contrato temporário em tudo se tornará a marca da vida pós-moderna. Por outro lado, o autor aponta uma importante discussão também relacionada à questão do tempo: "quanto maior a efemeridade, tanto maior a necessidade de descobrir ou produzir algum tipo de verdade eterna que nela possa residir" (HARVEY, 2012:263), o que pode ser explicado pelo acirramento de fundamentalismos e nacionalismos e interesse por instituições como a família e comunidade, que seriam indícios da procura de hábitos mais seguros e valores mais duradouros num mundo cambiante.

Torna-se claro, a partir de Harvey, a ênfase na aceleração do tempo com um marcante sintoma da nossa época, ponto corroborado por Fontenele:

\begin{abstract}
A sociedade das imagens como ela hoje se apresenta, é o resultado de um processo que começa no início do século XX, em função de uma ideologia do progresso técnico que levou à constituição de um tempo marcado pelo signo da velocidade e da organização burocratizada do emprego desse tempo [...] o ponto de chegada desse processo nos revela uma aceleração intensa e ininterrupta no sentido do tempo: a velocidade, a instantaneidade, a aceleração da aceleração (FONTENELE, 2002:24).
\end{abstract}

\title{
5. A TENSÃO ENTRE EFEMERIDADE E PADRONIZAÇÃO
}

$\mathrm{O}$ argumento de que a cultura se tornou descartável e volátil vai de encontro às conhecidas discussões sobre padronização e homogeneização como práticas principais da Indústria Cultural, amplamente difundidas desde os tempos de Adorno e Horkheimer, com a acusação da cultura ter sido incorporada pela produção em série: "num mundo organizado de 
Efemeridade e consumo contemporâneo: A circulação do capital no contexto da obsolescência programada

de Silvânia Mineira Ribeiro Sotttani

forma racional, o qualitativamente diverso só é objeto de repressão pela unidade da razão tecnológica" (ADORNO apud FONTENELE, 2002:288). Não se trata, hoje, da superação dessa visão crítica (e reconhecidamente pessimista), mas da sua consideração dentro da necessidade da indústria de produzir a sensação de perecibilidade enquanto mecanismo que mantém ativa e mais ágil a circulação de mercadorias.

Para autores filiados à EPIC, como César Bolãno, no caso das mercadorias culturais a inovação é amplamente limitada pela produção em série. "O próprio padrão de qualidade transforma-se assim numa camisa-de-força quando o 'conforto da previsão incita a reproduzir as linhas de produtos' e a evitar os riscos inerentes à inovação [...] o élan inovador reduz-se na mesma proporção que avança a planificação e o tipo de racionalidade econômica que ela implica" (BOLAÑO, 2000, pgs 185-186). A racionalidade econômica vai se tornando dominante na TV e tende a ser a regra para o funcionamento de toda a indústria cultural, não apenas no campo da distribuição ou reprodução, como apontavam os frankfurtianos, para incorporar-se também no processo de produção, "dominado por um complexo teórico-econômico que o procede e preforma" (BOLAÑO, 2000: 186) e onde mesmo o simbólico está incluído, como consumo potencial, na produção. Nessa "dialética da uniformização e da diferenciação", para Bolaño, entretanto,

a homogeneização, sendo uma exigência óbvia da massificação da produção cultural não pode jamais ser total, uma vez que a diferenciação é a mola da concorrência no capitalismo monopolista, onde vige a Indústria Cultural. Assim, a tensão entre homogeneização $e$ diferenciação do ponto de vista da oferta é permanente e incontornável (2000: 207).

Essa tensão também estaria localizada na produção de mercadorias tangíveis, carregadas de valores simbólicos, uma vez a necessidade de produção em larga escala, possível apenas pela homogeneização tanto dos bens produzidos quanto dos estilos e gostos da classe consumidora, ao passo em que a esses padrões não podem ser duradouros e arraigados de forma que não seja possível construir o sentido da efemeridade necessário à circulação mais ágil das mercadorias.

É Fontenele quem apresenta a fórmula que o capitalismo parece ter encontrado para superar essa tensão. Para a autora, a "solução" encontrada por essa indústria é a conjugação de imagens e produtos efêmeros com marcas duradouras.

a implosão constante de todas as formas resulta em uma cultura descartável, na qual a marca aparece como ilusão da forma. Em outras palavras, ao imenso vazio que se abre em função da cultura descartável pautada, predominantemente, pelo valor de troca, corresponde a produção incessante de imagens com as quais o capitalismo contemporâneo procura dar conta de tal vazio. 
Efemeridade e consumo contemporâneo: A circulação do capital no contexto da obsolescência programada

de Silvânia Mineira Ribeiro Sotttani

[...] não é a imagem, mas o nome da marca que importa, já que as imagens se deslocam o tempo todo em torno do nome, que é fixo. (FONTENELE, 2002:25).

A marca é, portanto, algo que se fixa e permanece, enquanto as imagens se sucedem indefinidamente, num paradoxo em que a marca tem que veicular imagens que se deslocam continuamente e, ao mesmo tempo, insistir no seu consumo, no padrão, que é o nome da marca. "Ao mesmo tempo em que precisa insistir no discurso da flexibilidade, da pluralidade, da liberdade de escolhas, da fugacidade dos modos de vida, também reforça o padrão, que é, em si mesmo, repetição. Uma tensão permanente que leva a marca a atuar em dois níveis: no deslocamento incessante das imagens e na fixação do seu nome" (FONTENELE, 2002:294). Esse ponto é corroborado por Harvey:

Ela [a imagem] se tornou, com efeito, o meio fugidio, superficial e ilusório mediante o qual uma sociedade individualista de coisas transitórias apresenta a sua nostalgia de valores comuns. A produção e a venda dessas imagens de permanência e de poder requerem uma sofisticação considerável, porque é preciso conservar a continuidade e a estabilidade da imagem enquanto se acentuam a adaptabilidade, a flexibilidade e o dinamismo do objeto, material ou humano, da imagem. (HARVEY, 2002: 260).

Temos, portanto, a tensão entre a manutenção do nome da marca (e da sua imagem construída) e necessária criação de discursos sobre a efemeridade que estimulem a circulação do capital, assim como de produtos postos à venda em ciclos cada vez mais ágeis, em que a "perecibilidade", hoje, mais do que um risco ao capital, configure-se como o seu grande trunfo. Essa constatação nos leva novamente a Marx: dada a necessidade da circulação cada vez mais rápida de novidades, quais os novos lugares dos tempos de trabalho aleatório e redundante? Ou, ainda: quais as consequências, na esfera da produção, para que a circulação seja mais veloz?

\section{EFEMERIDADE E A ESFERA DA PRODUÇÃO}

Quando falamos de criação ou invenção (inclusive de novos produtos), estamos caracterizando o chamado trabalho aleatório, ou seja, aquele permeado por alto nível de incerteza quanto aos seus resultados. É o que acontece, por exemplo, quando um estilista está criando uma nova coleção de moda: além da dificuldade de mensurar o tempo necessário e, ainda, a remuneração dessa forma de trabalho, o capital ainda tem que lidar com o fato de que nova coleção pode ou não atender aos anseios do mercado. "Os elementos de ordem subjetiva são 
Efemeridade e consumo contemporâneo: A circulação do capital no contexto da obsolescência programada

de Silvânia Mineira Ribeiro Sotttani

muito mais determinantes no caso dos bens simbólicos do que no dos bens materiais e, portanto, a aleatoriedade é maior" (BOLAÑO, 2000: 205).

Trata-se, pois, de um trabalho informacional, que caracteriza a informação mais valiosa quanto mais ela é capaz de transformar trabalho morto em trabalho vivo dando-lhe novas formas. "Em cada minuto, ou cada segundo, do processo de trabalho está havendo acréscimo de valor ao trabalho passado, devido às transformações que ele sofre, sob a ação útil do trabalho vivo" (DANTAS, 2006:53) ou, nos termos de Bateson, "informação é qualquer diferença que introduz uma diferença em algum evento posterior" (apud DANTAS, 2006: 47). Uma vez obtido esse evento novo (como os croquis de uma nova coleção), segue a produção de moldes e trabalho redundante: a produção/circulação das roupas da coleção, que acontece ao longo do tempo e com menor grau de incerteza, tal como ilustrado pelo gráfico abaixo:

Fig. 1 - Valor da informação-trabalho Fonte: Dantas, 2006: 51

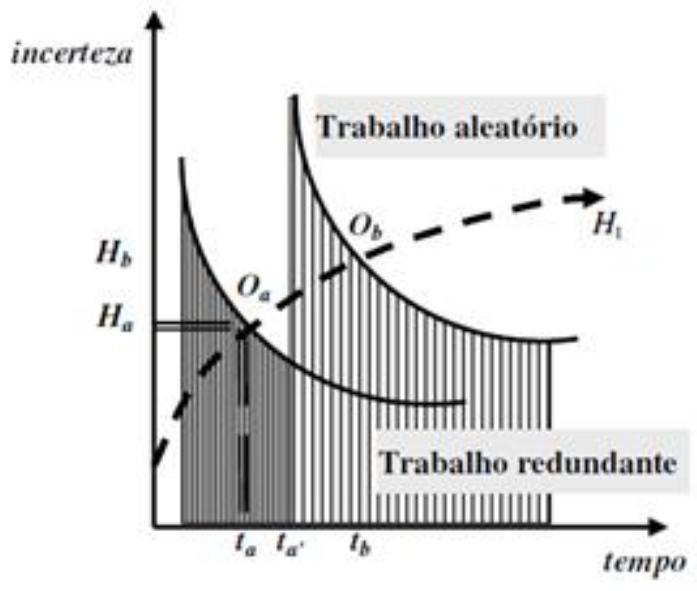

Considera-se, pois, de forma simplista, que há um ciclo em que se sucedem trabalho aleatório - montagem do molde - trabalho redundante - obsolescência - novo trabalho aleatório (e assim sucessivamente...), onde fica clara a necessidade de reduzir a incerteza e a aleatoriedade: "a presença da aleatoriedade está numa proporção inversa à formação de uma organização capitalista da produção e à possibilidade de planificação da audiência” (BOLAÑO, 2000: 195). Entretanto, a desvalorização rápida de certos produtos que têm que ser imediatamente trocados/substituídos no mercado, implica um curto tempo de ação da redundância e a necessidade de novos moldes que, por sua vez, pedem novo trabalho aleatório. Caso não haja esse novo trabalho aleatório, a tendência é haver estagnação e "morte", já que a 
Efemeridade e consumo contemporâneo: A circulação do capital no contexto da obsolescência programada

de Silvânia Mineira Ribeiro Sotttani

regra do modelo atual de sociedade prevê, de fato, a perecibilidade e a necessidade de substituição até mesmo de bens duráveis de forma cada vez mais ágil. Dessa forma temos um menor tempo de duração do trabalho redundante a partir de um molde, pela exigência constante de novidades, fruto de novos trabalhos aleatórios e um capital cada vez mais dependente do trabalho aleatório em espaços de tempo também cada vez menores, o que não quer dizer que o trabalho abstrato para produção material dos bens não tenha relevância, mas configura-se como inteiramente dependente do trabalho concreto/aleatório de criação ${ }^{4}$.

Isso leva à discussão sobre o valor na produção criativa. $\mathrm{O}$ valor deve ser procurado no fato de ser produção de um bem simbólico. "É isso que diferencia a Indústria Cultural de todas as demais indústrias capitalistas. O valor econômico da mercadoria cultural é acima de tudo o fruto da conversão de um valor simbólico" afirma Bolaño (2000: 199). É na ideologia que se deve procurar a substância do valor da mercadoria cultural, dada a concepção de que o valor simbólico é capaz de ser convertido em valor econômico e/ou político. Estes só podem ser adquiridos depois daquele. Nesse sentido, o valor simbólico é parte predominante do valor de uso da mercadoria. A unicidade pode ser importante na definição do valor de uso, mas principalmente o é a capacidade do produto cultural "preencher necessidades de ordem ideológica, psicológica e psicossocial, em substituição muitas vezes a outras instituições que, no processo de desenvolvimento do capitalismo foram perdendo legitimidade no campo da produção de valores simbólicos". (BOLAÑO, 2000: 202-203). Trata-se da estetização geral da produção capitalista - de bens culturais a quaisquer outros tipos de mercadorias. "Bens materiais também têm valor simbólico, também circulam como signos, como diria Baudrillard, e também estão sujeitos a um julgamento subjetivo do consumidor. Da mesma forma, a produção dos bens simbólicos se faz pela intermediação do capital econômico, de acordo com o seu modo específico de produção" (BOLAÑO, 2000: 204).

\section{CONSIDERAÇÕES FINAIS}

Todo o percurso desenvolvido nos mostra como é possível perceber a importância da efemeridade (e todas as características aí envolvidas, como velocidade, volatilidade, fragmentação, perecebilidade...) enquanto marca do atual modelo de sociedade, crescentemente pautada por valores simbólicos. Não se trata de negar a importância do valor material, já que

\footnotetext{
${ }^{4}$ Sobre as diferenças entre trabalho vivo concreto e trabalho redundante, ver: DANTAS, 2011.
} 
Efemeridade e consumo contemporâneo: A circulação do capital no contexto da obsolescência programada

de Silvânia Mineira Ribeiro Sotttani

cada valor simbólico carece de um suporte dessa natureza, mas da afirmação do intangível como predominante para a definição do valor econômico, em especial da noção de efêmero, amplamente apropriada pelos discursos do capitalismo contemporâneo para a reprodução do capital pela diminuição do tempo de circulação.

Longe de possibilitar qualquer outra afirmação contundente, as reflexões acima nos permitem levantar algumas questões. Essa redução no tempo de redundância, que leva à produção de novos moldes constantemente, tem um limite? Em que medida é possível reduzir o tempo de trabalho redundante cada vez mais? O valor de uso, mesmo simbólico, pode até ter curta durabilidade, mas precisa tê-la. Com o capitalismo vendendo cada vez mais valores simbólicos, que são consumidos imediatamente (tempo praticamente igual a zero), amplia-se a velocidade da necessidade de novo consumo, ou seja, de novas mercadorias carregadas de novos valores simbólicos fruto de trabalho aleatório. Mas a dependência do trabalho aleatório não vai na contramão da produção capitalista lucrativa? Essa aproximação do tempo ao limite de zero tratar-se-ia, portanto, do risco do capitalismo ter se apropriado da perecibilidade (ou da sensação de) para reduzir o tempo de circulação e garantir a sua expansão? Há algum limite, de fato, para a obsolescência programada com que atuam as empresas hoje?

Quando pensamos em exemplos como o lançamento do Fiat Palio 2013 (ocorrido em maio de 2012) ou a pré-coleção de outono da rede C\&A, lançada em 14 de janeiro de 2013 (menos de um mês depois do início do verão), as perspectivas nos parecem, no mínimo, um tanto instigantes...

\section{REFERÊNCIAS BIBLIOGRÁFICAS}

BOLAÑO, C. Indústria Cultural, Informação e Capitalismo. São Paulo: Hucitec, 2000.

DANTAS, M. Informação como trabalho e como valor. Revista da Sociedade Brasileira de Economia Política. Rio de Janeiro, 2006, nº 19: 44-72.

, M. Milionários nada por acaso. Revista de Economia Política de las Tecnologias de la Información y de la Comunicación. Vol. Xiii, n.2, maio-ago/2011.

DÉBORD, G. A Sociedade do Espetáculo. Rio de Janeiro: Contraponto, 1997.

EAGLETON, T. A Ideologia da Estética. Rio de Janeiro: Jorge Zahar, 1993.

FONTENELE, I. O Nome da Marca: McDonald's, fetichismo e cultura descartável. São Paulo:

Boitempo, 2002. 
Efemeridade e consumo contemporâneo: A circulação do capital no contexto da obsolescência programada

de Silvânia Mineira Ribeiro Sotttani

HARVEY, D. Condição Pós-Moderna. São Paulo: Loyola, 2012.

MARX, K. O Capital: crítica da economia política. Livro II, Seção I. Rio de Janeiro: Civilização Brasileira, 2008.

Artigo submetido: 02/09/2013

Artigo aprovado: 09/11/2014 